Contents List available at VOLKSON PRESS Intelligent Computing and Information Engineering (ICIE ) DOI : http://doi.org/10.26480/icie.01.2017.108.110 Journal Homepage: : https://www.intelcomp-design.com/

\title{
THE DESIGN OF LITHIUM BATTERY CHARGING CIRCUIT
}

Biqing $\mathrm{Li}^{1}$, Zhao $\mathrm{Li}^{2}$, Xuezhen $\mathrm{Li}^{1}$

${ }^{1}$ College of Mechanical and Electronic Engineering, Hezhou university, Hezhou Guangxi 542899, China.

${ }^{2}$ Management Engineering Department, Guangxi vocational and technical college of communications, Liuzhou Guangxi 545000, China.

*Corresponding author email: 229292710@qq.com

This is an open access article distributed under the Creative Commons Attribution License, which permits unrestricted use, distribution, and reproduction in any medium, provided the original work is properly cited

\section{ARTICLE DETAILS}

\section{Article History:}

Received 12 May2017

Accepted 12 July 2017

Available online 14 September 2017

Keywords:

The lithium battery, charging,

Single chip microcomputer.

\section{ABSTRACT}

This page proposed a Lithium battery charging circuit which used MCU AT89S52 as the core, consists of voltage regulator module, power supply switch module, lithium battery modules and prompt modules. It can be achieved precharge, fast charger, slow charger for the lithium battery charger; charging process presentation; disconnect the power after the battery is full automatically. The circuit has very high use value with the advantages of simple design.

\section{OVERALL DESIGN}

\subsection{Principle of operation}

Most of lithium ion battery used now are of graphite crystal for cathode and lithium cobalt oxide for anode [1,2]. Now take this battery for example to describe the basic operating principle of lithium ion battery: Graphite crystal and lithium cobalt oxide all have lamellar structure, which allows lithium ion to pass in and out, while irreversible conversion will not occur to material structure [3-5].

When charging battery, the lithium atoms in anode are ionized into lithium ions and electrons. The lithium ions that get input energy from exterior are moved from anode to cathode in electrolyte. The moving lithium ions and electrons bond lithium atoms on cathode, and the reformed lithium atoms are inserted into lamellar structure of graphite in cathode.

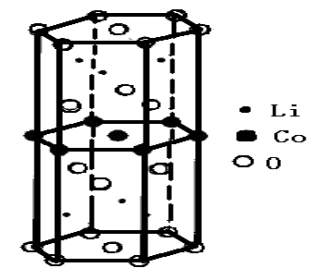

Figure 1: Schematic diagram for LiCoO2 lamellar structure

Charging temperature: Usually, the charging temperature of lithium ion battery is limited to be $0^{\circ} \mathrm{C} \sim 45^{\circ} \mathrm{C}$. Discharging temperature: Usually, the discharging temperature of lithium ion battery is limited to be $-20^{\circ} \mathrm{C} \sim 65^{\circ} \mathrm{C}$.Data of cycle life: greater than 1000 times when discharging depth is $10 \%$; greater than 200 times when discharging depth is $100 \%$. Storage characteristics: the capacity conservation rate of fully charged lithium ion battery conserved for about 25 days at ordinary temperature is averagely $96 \%$, and restoration ratio is above $99 \%$.

\subsection{Charging method of lithium battery}

Constant-current charge: The AC supply voltage of charger generally fluctuates, entailing to use a DC constant current source (charger) when charging [6] Constant-current charge can guarantee higher charge efficiency of battery, and enables users to decide whether to stop charging according to charging time conveniently, change quantity of batteries into the bargain.

\subsection{Quasi constant-current charge}

The circuit of quasi constant-current charge is as shown in figure 5. This circuit connects a potentiometer between DC power supply and battery in series to increase internal resistance of circuit to generate constant current [7]. The ohmic value used is adjusted according to current in later period of charging to make current not exceed allowable value of battery. As it has simple structure and low cost, this charge circuit is extensively used in charger circuit. 


\subsection{Major composition of system}

The design mainly takes 51 SCM STC89C52 as controller to design a lithium battery intelligent charging system, comprising SCM control circuit, voltagestabilizing switching circuit, optocoupler switching circuit, charge control circuit, indication alarm circuit, etc. Wherein, the voltage stabilizing circuit of power supply transforms $220 \mathrm{~V}$ commercial power into $5 \mathrm{~V}$ direct-current output for use by the whole system, and uses STC89C52 SCM to monitor each module circuit of the system in real time, to collect output signal of charge control circuit and decide whether to allow switching circuit to continue to supply power for it [8]. The charge control module detects information of lithium battery voltage/current, and decides charging state of lithium battery. The alarm prompt module prompts each state in charging process [9].

\subsection{Major functions enabled}

The functions enabled by this design are as follows:

Detect status of lithium battery. Charge and protect lithium battery. Automatic cut out power supply.

\subsection{Design of SCM control circuit}

SCM, also called microcontroller, is an integrated circuit chip that integrates microprocessor (CPU) with data processing capability, memory (containing program memory ROM and data memory RAM), input and output interface circuit (I/O interface) to one chip, thereby constituting a compact and perfect computer hardware system [10].

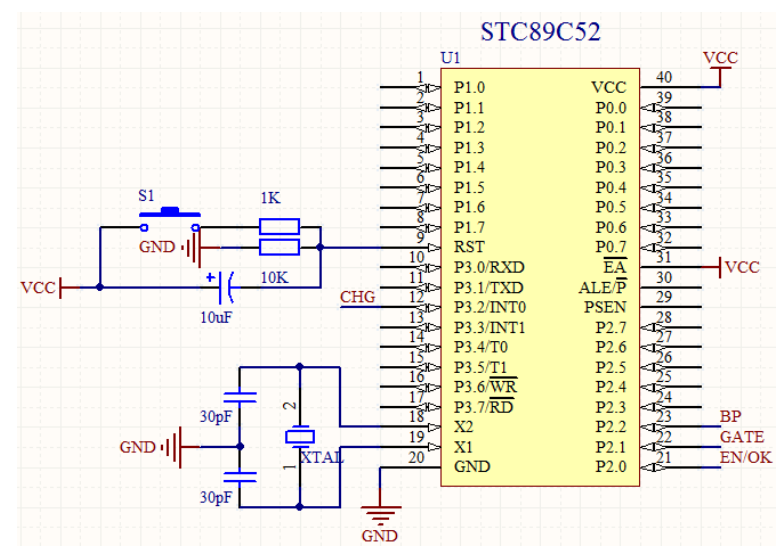

Figure 2: Minimal system diagram

\subsection{Charge control circuit}

MAX1898 is the core chip used by charge control circuit of this product. Following is an outline of MAX1898. Using MAX1898 and exterior transistor PNP or PMOS can constitute charger, now the users can charge with constant current/constant voltage accurately [11-14]. Usually the precision of battery voltage is as high as about $\pm 0.75 \%$. Currently there are two models of MAX1898, with MAX1898EUB42 applied to $4.2 \mathrm{~V}$ lithium ion battery, while MAX1898EUB41 applied to $4.1 \mathrm{~V}$ lithium ion battery.

\section{DESCRIPTION OF CHIP FUNCTIONS}

(1) Control accuracy of charging voltage is as high as $\pm 0.75 \%$

(2) Charging current can be set

(3) Provided with detection module for input power

(4) Inside is arranged with sense resister

(5) The user can set charging time

(6) Monitor magnitude of charging current in real time

(7) Restart function is optional

Application circuit

The figure below takes PNP as external connection transistor. In the figure, LED connects IN and $\overline{C H G}$ to serve as charging state indicator. Battery (BATT) is earthed with $10 \mathrm{uF}$ shunt capacity to make lithium ion battery charge stably. Schottky diode is connected between drain electrode/collector of external transistor and BATT anode, to prevent battery from discharging to damage chip when input power supply is short circuited. The design sets charge duration as 3 hours, maximal charging current as $250 \mathrm{~mA}$ and uses automatic restarting function, so connects externally $0.1 \mathrm{uF}$ capacitor via CT, connects externally 5.6K resistance via ISET, and earths via RSTRT $[15,16]$.

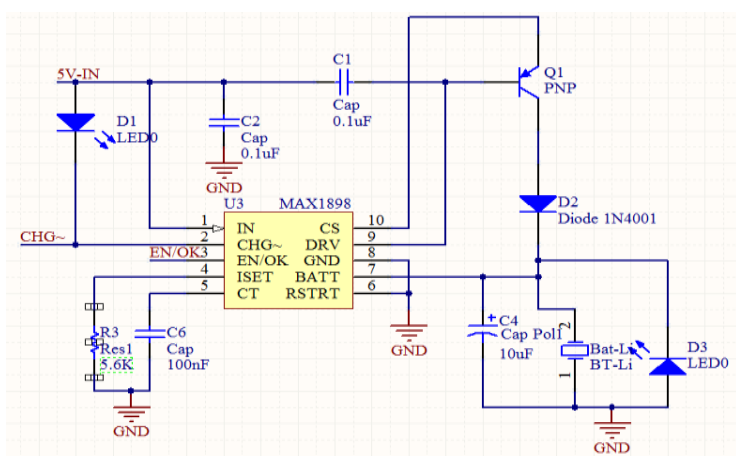

Figure 3: MAX1898 connection graph 
When the battery is fully charged, the product is designed as LED flashing and buzzer alarming to prompt the users to take out battery timely. The connection of alarm circuit is relatively simple. The connection circuit is as shown in figurer below.

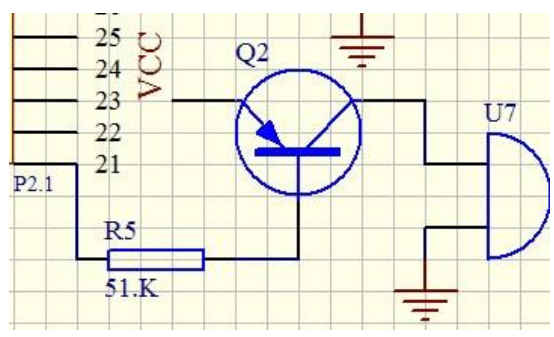

\section{SUMMARY}

Figure 4: Alarm circuit

The paper describes fundamentals for quick charging of lithium ion battery and designs a charger charging 4.2V lithium ion battery, which can rapidly charge lithium ion battery.

This work is supported the following fund:2016 The project of improving the basic ability of young teachers in Colleges and universities in Guangxi:"Design and development of electronic commerce platform of agricultural products based on Semantic Technology"(No,KY2016YB455).2015 college students' innovative training program: "Research on the application of value added travel experience in the mobile terminal of the 'ethnic custom travel' in Guangxi" (No 201511838070);\&\& “The design and development HeYuanTong Campus Mobile Phone APP based on Android" (No 201511838034).Project of scientific research and technology development project of Hezhou: "Design and implementation of agricultural products e-commerce platform based on Semantic Technology" (No,Hekeneng 1506006).

\section{REFERENCE}

[1] Li, B.Q., Ling, Y.F., Zhang, H.Y., Zheng, S.Y. 2016. The Design and Realization of Cherry Tomato Harvesting Robot Based on Iot. International Journal of Online Engineering, 12 (12), 23.

[2] Li, B.Q., Guan, W.L., Zheng, S.Y., Yue, X.G. 2015. Optimisation Design of Corn Precision Seeder Based on Multi-Route and Multi-Channel Control. Journal of The Balkan Tribological Association, 21(4a), 1215.

[3] Zheng, S.Y., Li, Z., Li, B. 2015. Social Work In Teen Addiction Correction Services Research Under The New Situation, In: Proceedings Of The 2015 4th National Conference On Electrical, Electronics And Computer Engineering (Nceece 2015), Xian, China, 252-255.

[4] Li, B.Q., Li, Z., Wei, L. 2016. Intelligent Control Management System And Its Application, In: Proceedings Of The 2016 International Conference On Economics And Management Innovations, Wuhan, China, 68-71.

[5] Li, B.Q. 2016. Design and Implementation of Tanks War Game Based On The Android Platform, In: Proceedings Of The 2016 2nd Workshop On Advanced Research And Technology In Industry Applications, Dalian, China, 963-966.

[6] Li, B.Q. 2016. Design of A Tea Garden Ant freezing Control System, In: Proceedings Of The 2016 6th International Conference On Machinery, Materials, Environment, Biotechnology And Computer (Mmebc), Tianjin, China, 736-738.

[7] Li, B.Q. 2016. Design of Electronic Compass, In: Proceedings of The 2016 6th International Conference On Machinery, Materials, Environment, Biotechnology And Computer (Mmebc), Tianjin, China, 1240-1243.

[8] Li, B.Q. 2016. Research of Automatically Light-Adjusting Lamp, In: Proceedings Of The 2016 International Conference On Computer Engineering Information Science and Application Technology (Iccia 2016), Guilin, China, 249-252.

[9] Li, B.Q. 2016. The Design And Realization Of Fruit Harvesting Robot Based On Iot, In: Proceedings Of The 2016 International Conference On Computer Engineering, Information Science and Application Technology (Iccia 2016), Guilin, China, 261-264.

[10] Li, B.Q. 2016. A New Type of Automatic Opening And Closing Light-Operated Curtain, In: Proceedings Of The 2016 International Conference On Mechatronics Engineering And Information Technology (Icmeit), Xian, China, 66-69.

[11] Li, B.Q. 2013. Design of The Intelligent Air Humidifier, In: Proceedings of The 2016 International Conference On Mechatronics Engineering And Information Technology(Icmeit), Xian, China, 201-203.

[12] Li, B.Q. 2016. The Design Implementation of The App of Experiencing Guangxi Folk Custom, In: Proceedings of The 2016 International Conference On Economics And Management Innovations, Wuhan, China, 47-50.

[13] Zheng, S.Y. 2015. Digital Display Design of Ethnic Clothing Of Nanling, In: Proceedings Of The 4th International Conference On Mechatronics, Materials. Chemistry And Computer Engineering 2015 (Icmmcce 2015), Xian, China, 2805-2808.

[14] Zheng, S.Y. 2015. Design And Implementation Of Supermarket Personnel Management System Based On Java, In: Proceedings Of The 2015 International Conference On Education,Management And Computing Technology, Tianjin, China, 1724-1727.

[15] Zheng, S.Y. 2016. Analysis Of Internet Of Things Talent Training And Curriculum System Innovation, In: Proceedings Of The 2016 International Conference On Education,Management And Computing Technology (Icemct-16), Hangzhou, China, 957-960.

[16] Zheng, S.Y. 2015. Brief Analysis On "Heyuantong" Campus Mobile Phone App Design, In: Proceedings of The 2015 5th International Conference On Computer Sciences And Automation Engineering, Sanya, China, 151-154. 